\title{
Шелковый путь - коридор новых возможностей или показатель непреодолимой отсталости востока России? ${ }^{1}$
}

\author{
Н.И. АТАНОВ, доктор экономических наук, Бурятский государственный \\ университет, Улан-Удэ. E-mail: ni.atanov@yandex.ru
}

Анализ муниципальных экономик Республики Бурятия обнаружил чрезвычайно низкие стартовые условия последних для встраивания в международное разделение труда при наличии значительных резервов повышения экономических возможностей. Предложены меры на местном, региональном и федеральном уровнях, чтобы муниципальные экономики субъектов РФ стали конкурентоспособными и реализовали свой шанс для встраивания в торгово-экономические цепочки внешнего рынка, включая ЕАЭС и ВШП.

Ключевые слова: Великий шелковый путь, Евразийский экономический союз, экономический коридор, муниципальные районы, локальная экономика, Республика Бурятия, Байкальский регион

\section{Вызов или шанс?}

Набирающий ускорение сдвиг глобальной экономической активности в направлении Тихоокеанской Азии - позитивный сигнал для встраивания в этот тренд экономик регионов России, прежде всего, восточных. Причина кроется не столько в пространственном факторе, сколько в растущей емкости рынков Центральной и Восточной Азии, и этой возможностью грех не воспользоваться. Для этого руководством России предпринимаются соответствующие меры: 28.10.2015 г. Правительство РФ приняло Концепцию развития приграничных территорий субъектов Российской Федерации, входящих в состав Дальневосточного федерального округа, включая Байкальский регион ${ }^{2}$; 26 июля 2017 г. Президент РФ В.В. Путин утвердил федеральный

\footnotetext{
${ }^{1}$ Статья подготовлена при финансовой поддержке Российского научного фонда (проект 17-22-03003).

${ }^{2}$ Концепция развития приграничных территорий субъектов Российской Федерации, входящих в состав Дальневосточного Федерального округа. Распоряжение Правительства Российской Федерации от 28 октября 15 года № 2193-p. [Эл. ресурc]. URL: http://docs. cntd.ru/document/420313859
} 
закон «Об основах приграничного сотрудничества» ${ }^{3}$. На Саммите ШОС в Ташкенте 28 июля 2016 г. руководителями России, Китая и Монголии утверждена совместная программа создания экономического коридора Китай-Монголия-Россия ${ }^{4}$. Запущены в действие и другие законодательные, нормативные и программные документы. Субъекты РФ активно готовят Стратегии развития на 2019-2035 гг., в которых внешнеэкономический акцент ориентирован на восточное направление сотрудничества.

По мнению исследователей Института экономики и организации промышленного производства СО РАН, «облачный» характер документа «Один пояс и один путь» открывает значительные возможности для повышения устойчивости социально-экономического развития востока России» [Восток России.., 2017. С. 284].

Перед восточными регионами России открылись и шанс, и вызов одновременно: либо, воспользовавшись «коридором возможностей», построить конкурентоспособную, динамично развивающуюся, экспортоориентированную экономику, либо остаться в роли транзитной территории, обслуживающей проносящийся мимо экономический экспресс, плетясь в хвосте экономического, технологического и социального прогресса.

Шанс еще в том, что без внешнего акселератора в лице открывающихся рынков Евразийского экономического союза и Великого шелкового пути, невозможно одними местными силами изменить сложившуюся на восточных окраинах России статику со слабо пульсирующим точечным развитием.

Однако реализации «благих пожеланий и заслуживающих внимания подходов и проектов на востоке России препятствуют не только недооценка роли транспортной инфраструктуры в решении проблем социально-экономического развития, но и приниженная роль регионов и муниципалитетов востока России в хозяйственной сфере в целом» [Восток России.., 2017. С. 284].

\section{Интерьер муниципальной экономики региона}

Анализу причин депрессивного положения экономик Забайкальской и Дальневосточной России журнал «ЭКО» в 2014 г.

\footnotetext{
${ }^{3}$ Федеральный закон об основах приграничного сотрудничества от 26 июля 2017 года № 179-ФЗ. [Эл. peсурс]. URL: http://www.garant.ru/products/ipo/prime/doc/71630188

${ }^{4}$ Программа создания экономического коридора Китай-Монголия-Россия. [Эл. pecypc]. URL: http://news.mongolnow.com/assets/rus-ch-mn.pdf
} 
посвятил серию статей [Атанов и др., 2014; Калугина, 2014; Соболева и др., 2014]. Ситуация остается неразрешенной и поныне. Рассмотрим положение дел на материалах Республики Бурятия.

В республике 23 административно-территориальных образования. В аналитическую выборку включены пять пограничных ${ }^{5}$ сельских муниципальных районов (22\%), которые непосредственно граничат с сопредельными аймаками Монголии, и в историческом аспекте между ними сложились определенные связи. Отметим, что социально-экономическая ситуация в пограничье ретранслируется во всех сельских муниципальных районах Бурятии, ввиду аналогичности проблем и возможностей. При этом пограничные территории являются своего рода форпостами государства, лимитрофами на пограничных рубежах.

Пограничные Джидинский, Закаменский, Кяхтинский, Окинский и Тункинский муниципальные районы занимают 19\% территории Бурятии, на которой проживает 11,8\% численности населения с плотностью 1,73 чел./км², против 2,8 в среднем по региону (таблица). Лидирующая позиция среди них по транспортной, пограничной и таможенной инфраструктуре принадлежит Кяхтинскому району. Отдельная тема - районный центр - г. Кяхта, сыгравший в XVIII-XIX веках огромную роль в развитии российско-китайских политических и торговых взаимосвязей. Великий чайный путь из Китая в Россию и далее в Европу имел в «Песчаной Венеции», как величали Кяхту, развитый по тем временам торгово-логистический центр. И сегодня через Кяхтинский район проходит транспортный коридор Россия-Монголия-Китай с железнодорожным и автомобильным сообщениями, который по расстоянию до Пекина на 1200 км короче основной артерии Чита-Забайкальск-Маньчжурия. В г. Кяхта действует международный автомобильный пункт пропуска через госграницу, а в поселке городского типа Наушки - железнодорожный пункт пропуска.

\footnotetext{
${ }^{5}$ В федеральном законе «Об основах приграничного сотрудничества» к приграничным отнесены субъекты РФ, территории которых прилегают к государственной границе (ст. 2, п. 2), то есть все муниципальные образования данного субъекта являются приграничными. Поэтому для выделения в их составе непосредственно приграничных MO, нами введен в оборот понятие «пограничные муниципальные районы».
} 
Общая характеристика пограничных муниципальных районов Республики Бурятия

\begin{tabular}{|l|c|c|c|c|c|l|}
\hline \multirow{2}{*}{$\begin{array}{c}\text { Муниципаль- } \\
\text { ные районы }\end{array}$} & \multicolumn{2}{|c|}{ Территория } & \multicolumn{2}{|c|}{ Население } & \multicolumn{1}{|c|}{ Плотность } \\
\cline { 2 - 6 } & км². & $\begin{array}{c}\text { в \% } \\
\text { к терри- } \\
\text { тории РБ }\end{array}$ & $\begin{array}{c}\text { тыс. } \\
\text { чел. }\end{array}$ & $\begin{array}{c}\text { Доля в общей } \\
\text { численности } \\
\text { РБ, \% }\end{array}$ & $\begin{array}{c}\text { населе- } \\
\text { ния, чел/ } \\
\text { км }{ }^{2}\end{array}$ & $\begin{array}{c}\text { Сопредельные } \\
\text { аймаки Монголии }\end{array}$ \\
\hline Джинский & 8,6 & 2,5 & 25,0 & 2,5 & 2,9 & $\begin{array}{l}\text { Сэлэнгэ и опосредо- } \\
\text { ванно Дархан-Уул }\end{array}$ \\
\hline Кяхинский & 4,7 & 1,3 & 37,8 & 3,8 & 8,0 & $\begin{array}{l}\text { Сэлэнгэ и опосредо- } \\
\text { ванно Орхон }\end{array}$ \\
\hline Закаменский & 15,3 & 4,3 & 26,4 & 2,7 & 1,7 & $\begin{array}{l}\text { Булган и опосредо- } \\
\text { ванно Дархан-Уул }\end{array}$ \\
\hline Окинский & 26,6 & 7,6 & 5,4 & 0,5 & 0,2 & Хубсугул \\
\hline Тункинский & 11,8 & 3,3 & 21,2 & 2,2 & 1,9 & Хубсугул \\
\hline Итого & 67,0 & 19,0 & 115,8 & 11,8 & 1,73 & \\
\hline
\end{tabular}

Источник: здесь и далее аналитический материал по Республике Бурятия составлен автором на основе Статистического сборника Бурятстата ${ }^{6}$

Связи с Монголией через Хубсугульский аймак осуществляются по двустороннему автомобильному пункту пропуска Монды-Ханх в Тункинском районе. Еще в двух районах - Джидинском и Закаменском, ведется строительство/реконструкция автомобильного пункта пропуска. Без прямой связи с Монголией остается Окинский район. Отметим, что в период советско-монгольского сотрудничества (до 1992 г.) действовало 12 пунктов перехода, из которых девять были сезонными и функционировали в период активных сельскохозяйственных работ.

Пограничные районы по определению - окраинные, т.е. наиболее отдалены от центров культурной и деловой активности: расстояние между районными центрами и столицей РБ - г. УланУдэ составляет от 230 до 770 км.

По демографическому положению ситуация медленно смещается в направлении обезлюживания, что характерно для многих пограничных регионов Сибири [Соболева и др., 2014; Калугина, 2014]. Если за 2016 г. отрицательное сальдо миграции по Республике Бурятия составило 2006 человек, то по пограничным районам - 2537 человек. Удельный вес населения старших возрастных групп составляет: по республике - 26,5\%, в пограничных районах - 28\%. Коэффициент рождаемости

\footnotetext{
${ }^{6}$ Статистический ежегодник. 2017. Статистический сборник / Бурятстат. Улан-Удэ, 2017.
} 
за 2011-2015 гг. по Бурятии имеет положительную динамику $(101,7 \%)$, а во всех пяти пограничных районах имеет тенденцию к снижению: 92\% - в Джидинском районе, по 86\% - в Закаменском и Кяхтинском районах, по 93\% - в Окинском и Тункинском. В итоге естественный прирост равен $100 \%$ только в Тункинском районе, 64,1\% - в Закаменском, 87,3\% - в Джидинском, 89,4\% в Кяхтинском, 93\% - в Окинском районах. Налицо процесс депопуляции.

Потенциал локальных экономик пограничных районов также не отличается положительными или опережающими тенденциями роста. По количеству субъектов экономической деятельности (при удельном весе численности населения - $11,8 \%$ и занимаемой территории - 19\%) число предприятий и организаций составляет всего $6,6 \%$ от общего по республике, в том числе в сельском и лесном хозяйствах $-10 \%$, в добыче полезных ископаемых и в обрабатывающих производствах - по 3,4\%, в строительстве $-1,5 \%$, в оптовой и розничной торговле $-5,4 \%$, транспорте и связи $-2,9 \%$. Зато в госуправлении, обеспечении безопасности, социальном обеспечении $-23 \%$, в системе образования $-18,4 \%$, здравоохранении $-10,5 \%$.

Об аграрной специализации пограничных районов свидетельствует их доля в валовом сельскохозяйственном продукте республики, равная $24 \%$. Лучше всего развито животноводство - $28 \%$ (30,7\% в 2013 г.). Если по республике поголовье скота в расчете на душу населения составляет 0,86 голов, то в пограничных

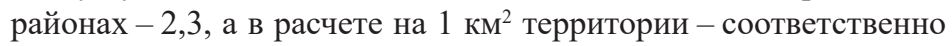
4 и 2,4 головы ${ }^{7}$. При этом мясокомбинаты действуют только в Джидинском и Закаменском районах, промышленная переработка молока - только в Кяхтинском районе.

Неутешительные демографические и экономические характеристики обусловили догоняющие позиции пограничных районов по уровню жизни. Среднемесячная номинальная начисленная заработная плата работников предприятий и организаций ниже среднего по региону на 4,5 тыс. руб. (86\%), среднемесячный размер социальной поддержки одного пользователя составляет 267,8 руб. против 352 руб. в среднем по Бурятии.

${ }^{7}$ Для сравнения: в среднем по Монголии на 01.01.2017 г. поголовье скота на душу населения составляло 22,3 гол., на 1 км²$^{2}-43$ гол. 


\section{Приграничные взаимодействия}

Организованное торгово-экономическое взаимодействие с сопредельными монгольскими аймаками Сэлэнгэ, Булган и Хубсугул у пограничных районов РБ отсутствует [Атанов, Мункодугарова, 2014]. В челночной торговле лидируют монгольские коммерсанты. Помимо завоза монгольских и китайских товаров, они в сезон закупают картофель и овощи у местного населения для дальнейшей перепродажи не только на своей территории, но и в городах Улан-Удэ, Гусиноозерск.

Проблемы бурятских пограничных районов со встраиванием во внешнеторговые цепочки объясняются, с одной стороны, крайне ограниченными объемами и структурой производимой продукции. С другой (и это более фундаментальная причина) - кроются в ментальности местного населения, его неумении торговать, ограниченных предпринимательских способностях. К сожалению, на протяжении 70 лет существования СССР предприимчивость в народе идентифицировалась со спекуляцией - уголовно наказуемой и порицаемой обществом. «Палочная» дисциплина на производстве купировала инициативность трудящихся. В итоге сегодняшняя экономика в селах на 65-70\% поддерживается личными подворьями наиболее трудолюбивых крестьян. Стратегия адаптации к рыночному укладу у большинства сельского населения не поднялась выше уровня подворного ведения хозяйства [Гудков, Дубин, 2002].

Отметим, что формально между пограничными районами Бурятии и сопредельными аймаками Монголии существуют соглашения о сотрудничестве. Но из всей совокупности пунктов этих документов лишь один выполняется более или менее исправно. Это проведение праздника «Древо согласия». Праздник имеет глубокие исторические корни. В этот день открывались границы, граждане обеих стран встречались, шла бойкая торговля, проходили спортивные состязания, концерты художественной самодеятельности, обсуждались и строились планы сотрудничества на будущее. Праздник по-прежнему проводится ежегодно, поочередно на территориях сторон по заранее спланированному графику. Но уже без открытых границ. 


\section{Экстерьер отечественного приграничья: чем и как достичь опережающего развития?}

Статус пограничных районов не дает никаких бонусов и преференций муниципальным образованиям, а наоборот, накладывает дополнительные нагрузки и затраты, многие из которых связаны с реализацией федеральных компетенций.

Пограничная полоса шириной 5 км вдоль границы ограничивает ведение на ней строительных и хозяйственных работ, то есть фактически изымает из оборота приличную территорию. Это негативно сказывается не только на возможностях развития скотоводческой отрасли, но и предпринимательской инициативе. Так, невозможно решить вопрос о строительстве транспортнологистической и туристической инфраструктуры в непосредственной близости от пунктов перехода госграницы (что логично вписывается в критерии экономической целесообразности).

Режим разрешительного въезда на пограничную территорию для граждан России - нерезидентов пограничного района, существенно сдерживает бизнес-инициативы. К тому же жители пограничных районов практически постоянно пребывают в состоянии готовности к разного рода нештатным ситуациям: тушению трансграничных пожаров; пресечению миграции диких и домашних животных с монгольской стороны, во избежание переноса разного рода болезней скота (от ящура и сибирской язвы до сапа). Особая проблема - набеги с монгольской стороны волков, задирающих местный скот. Поэтому в поселениях созданы дружины, «на общественных началах» организовываются дежурства и патрулирование вдоль границы.

Наибольшая нагрузка ложится на администрацию Кяхтинского района, выполняющую, помимо прочего, «дипломатические» функции по организации встреч и проводов официальных лиц и делегаций России, Монголии и третьих стран, пересекающих госграницу через МАПП-Кяхта и ЖДПП-Наушки.

Реальное воплощение функции форпоста и фасада страны, стремящейся войти в пятерку мировых лидеров, предполагает проведение основательной модернизации пограничных территорий по примеру Китая на основе Концепции развития приграничных территорий субъектов Российской Федерации, 
входящих в состав Дальневосточного федерального округа ${ }^{8}$. Пунктом 2 раздела IV Концепции предусмотрено придание территории приграничных муниципальных образований особого статуса и формирование перечня первоочередных мероприятий по реализации их опережающего социально-экономического развития.

Отличительной особенностью данной госпрограммы является то, что она должна быть тесно увязана со Стратегией пространственного развития РФ и Стратегией социально-экономического развития Дальнего Востока и Байкальского региона. А трехстороннее соглашение по созданию экономического коридора Китай - Монголия - Россия и вовсе напрашивается на роль технического задания.

В свою очередь пограничные субъекты РФ, разрабатывающие собственные стратегические документы социально-экономического развития, в том числе в разрезе муниципальных районов, во исполнение «майского» Указа Президента «О национальных целях и стратегических задачах развития Российской Федерации на период до 2024 г.» ${ }^{9}$, в качестве одной из целевых установок должны избрать создание экспортоориентированной экономики с глобальной конкурентоспособностью. Для муниципальных районов Бурятии это пионерная постановка цели. Ни один из сельских районов республики не является на сегодня субъектом международной кооперации.

Казалось бы, наиболее логичной сферой приложения усилий в организации трансграничной торговли является рынок полуторамиллиардного Китая, у которого есть неудовлетворенный спрос на все виды продовольственных товаров сибирско-дальневосточной специализации. Но! Разрозненное вхождение отдельных муниципалитетов и даже регионов на этот рынок, на наш взгляд, не обеспечит на нем успеха. Более того, отечественные локальные экспортеры, ввиду отсутствия опыта, скорее всего начнут конкурировать друг с другом, что легко может обернуться игрой на понижение цен со стороны китайских партнеров. Ярким отрицательным примером может послужить неудачная попытка лесоэкспорта в 1990-2000-е гг. Тогда, в условиях

\footnotetext{
${ }^{8}$ Утверждена распоряжением правительства РФ 28 октября 2015 года № 2193-р

9 Указ Президента Российской Федерации от 7 мая 2018 года. [Эл. ресурc]. URL: http://prezident.org/articles/ukaz-prezidenta-rf-204-ot-7-maja-2018-goda-07-05-2018.html
} 
острого дефицита оборотных средств и ограниченного сбыта внутри страны, новообразованные частные лесозаготовительные компании поодиночке ринулись на внешние рынки. Именно в это время основным импортером сибирской древесины стал Китай, перехвативший этот статус у Японии, но, в отличие от нее, предъявлявший спрос преимущественно на сырье низкой степени обработки. Отсутствие у российских поставщиков достаточного опыта и жажда быстрой наживы сыграли на руку китайским импортерам: экспортная цена пиловочника хвойных пород снизилась на 30-35\%. В свою очередь местные деревообрабатывающие предприятия, оставшись без сырьевой базы, оказались обречены на банкротство (отметим, что принципиальное решение идеологов реформ о раздельной приватизации лесозаготовительных и деревообрабатывающих предприятий в итоге сыграло губительную для отрасли роль)...

Одним словом, лучше всего, если все три субъекта РФ Байкальского региона будут действовать на экспортном направлении сообща. Им необходима кооперация для достижения конкурентоспособных объемов «зеленого» экспортного потенциала, что, в свою очередь, требует объединения действий на таких направлениях, как подъем племенного и зооветеринарного дела, семеноводства, почвоведения, биотехнологий, маркетинга, логистики и т.д.

Пионерами и ведущими экспортными секторами байкальского приграничья, на наш взгляд, по праву выступят животноводство и акваэкономика, а за ними все остальные отрасли аграрной специализации.

В животноводстве экспортные резервы для Бурятии скрыты опять же в кооперации: внутри России - со смежными Забайкальским краем и Иркутской областью; за рубежом - с монгольским аратами. В первую очередь - в области создания совместной научно-инновационной платформы, призванной нормализовать эпизоотическую обстановку, повысить продуктивность скота и его устойчивость к различного рода заболеваниям, наладить комплексную переработку всего исходного сырья, организовать подготовку и повышение квалификации кадров, обеспечить развитие биотехнологий и перевод отрасли на принципы «зеленой» экономики. У каждой из заинтересованных сторон есть что предложить в «общий котел» кооперации в области ветеринарии, зоотехнологии, племенного дела, кормопроизводства, пищевых 
технологий, технологий лёгкой промышленности, экспериментальной и приборной базы. Наконец, немаловажное значение имеет совместная выработка взвешенной торговой политики по отношению к такому непростому рынку, как китайский.

Акваэкономика может стать новым стратегическим направлением специализации экспортного бизнеса Бурятии с учётом тенденции растущего глобального вододефицита. Имея и добывая большое количество чистой питьевой воды, Бурятия уже сегодня является ее донором для соседних регионов. Вопрос, по сути, стоит в конвертации этого донорства в рентный доход. Наилучшее решение в извлечении такого дохода-это экспортная выручка. Имеющаяся сырьевая база практически не ограничивает возможности производителей (даже без учёта запасов воды в озере Байкал). Пять местных предприятий, занимающихся добычей и реализацией питьевой воды на внутреннем рынке, накапливают опыт для перехода на международный уровень торговли. Фактически отрасль стоит «на низком старте» своего экспортоориентированного развития.

Однако считаем необходимым как можно более тщательно проработать вопрос о допуске иностранных инвесторов к созданию предприятий по добыче, подработке и розливу воды для вывоза на внешние рынки. На наш взгляд, россиянам в укор допуск чужестранцев к своим природным кладовым. Мы сами должны свое добывать, производить и торговать. Еще больший абсурд (политический и экономический) - набирающая обороты тема прокладки водовода от озера Байкал на китайском направлении.

«Зеленый» экспорт продовольственных товаров необходимо дополнить экспортом саженцев засухоустойчивых деревьев и кустарников для лесомелиорации граничных зон пустыни Гоби как с монгольской, так и китайской стороны. Монголия уже несколько десятилетий испытывает дефицит лесомелиоративного материала, что сдерживает реализацию ее национальной экологической программы «Экотрасс» по лесозаграждению граничных зон в пустыне Гоби. Незначительные объемы импорта из Бурятии саженцев облепихи не решают проблему. Аналогичная проблема борьбы с наступлением песков Гоби на обжитые территории имеется и в Китае. На наш взгляд, оказание помощи нашим соседям в лесомелиоративной защите территории могло бы иметь не только экологический, социальный и экономический смысл, 
но и политическое значение - в свете реализации трехсторонней программы по созданию экономического коридора Китай-Монголия-Россия.

Однако в самой Бурятии до недавнего времени перспективы нового направления «зелёного» экспорта саженцев на официальном уровне не рассматривались. Лесное хозяйство региона целиком поглощено проблемами предотвращения пожаров, незаконной вырубки и перманентных реформ (не до экспорта). Эта тема нашла отражение лишь в проекте новой Стратегии социально-экономического развития Республики Бурятия до 2035 года. Новизна её и масштабы предполагают серьезную проектную проработку, в которой ведущую позицию, очевидно, займет создание лесопитомников с современной технологий интенсивного выращивания саженцев (последние, заметим, нужны не только для экспорта, но и для восстановления собственной биосферы). На наш взгляд, учитывая сказанное, не только Бурятия, но и весь Байкальский регион мог бы стать пионерной экоплощадкой национальной российской программы по восстановлению лесов.

Недостаточно используемым резервом всего Байкальского региона является бальнеологический потенциал [Шагжиев, Бабиков, 2016]. Более 300 минеральных источников в Бурятии, около 400 - в Забайкальском крае и Иркутской области ждут своего освоения как для розлива и продажи минеральной воды, так и для создания санаториев и курортов, в дополнение к уже действующим. В Бурятии этот потенциал используется лишь на 5\% (в 15 здравницах), еще 290 источников нуждаются в доразведке запасов, биохимическом анализе воды и грязей, создании приемлемой инфраструктуры, а пока используются в основном населением близлежащих сел в летне-осенний период. Между тем оздоровительный туризм - самый привлекательный из всех других туристических направлений [Ветитнев, Торгашева, 2013].

В этой связи следует вспомнить недавнюю неудачную попытку создания ОЭЗ «Байкальская гавань». Причиной провала проекта, на наш взгляд, стали недоработки в определении его концепции и преувеличенные ожидания от рекреационного потенциала озера Байкал. Так, в границы ОЭЗ не был включен даже находящийся от нее в 3 км курорт Горячинск, созданный еще в 1904 г. и имевший статус общесоюзного. Очевидно, уроки прошлых ошибок должны помочь дальнейшую политику 
развития туристического бизнеса в Бурятии переориентировать в первую очередь на оздоровительные услуги.

Ключевой проблемой, требующей безотлагательного решения и перманентного внимания, является формирование и развитие институтов управления внешнеэкономической деятельностью регионов и муниципальных образований в их составе. В муниципалитетах Республики Бурятия институты надо создавать заново, а в региональном правительстве - централизовать соответствующие функции в едином органе.

Институты управления экспортным направлением специализации экономики, исходя из опыта стран, добившихся успеха в этой сфере, должны определять всю экономическую политику регионов, включая постановку задач для секторов, работающих на внутренний рынок и выбор направлений международной торговли и кооперации.

Республика Бурятия имеет все необходимые условия и ресурсы, чтобы стать провайдером внешней политики России на страны Восточной Азии в качестве «мягкой силы». Это самая восточная автономия России, сопряженная с самой северной территорией буддийского конфессионального мира в лице Монголии. B XIX и начале XX века бурятские деятели - Агван Доржиев, братья Бадмаевы, Гомбожап, Цыбиков, Цэвэн Жамсарано, Эрдэни Батухан, Михаил Богданов, Матвей Амагаев, Элбэг-Доржи Ринчино и др. - служили на благо России в продвижении ее политики на Монголию, Китай, Тибет, Индию. А Мария Сахьянова имеет прямое отношение к созданию коммунистической партии Китая в первой четверти XX века. Сегодня в Бурятии действует буддийская сангха России, Институт монголоведения, буддологии и тибетологии СО РАН, Восточный институт и филиал Института Конфуция в Бурятском госуниверситете, в Бурятском научном центре создан богатейший фонд восточных рукописей... Этот потенциал необходимо задействовать.

Кроме того, ренессанс былого величия Кяхты, когда-то имевшей статус «вольного города», предполагает создание на ее территории зоны свободной торговли в экономическом коридоре ВШП и ЕАЭС, а также открытие Евразийского коммерческого колледжа для подготовки кадров для внешней торговли и международной кооперации. В свою очередь г. Улан-Удэ мог бы взять на себя часть представительских и торгово-экономических 
функций Евразийского экономического союза на монгольскокитайском направлении, включая проведение конгрессных мероприятий (форумов, саммитов, конференций, деловых и дипломатических встреч).

\section{В заключение}

Экономический коридор Великого шелкового пути и Евразийского экономического союза может стать для Республики Бурятия и смежных регионов коридором новых возможностей для встраивания их экономики в торгово-экономические цепочки, при условии замещения идеологии выживания парадигмой открытости, когнитивности, экспорто-ориентированного развития экономики. Усилий только региональной и местной элит будет недостаточно, чтобы «разморозить» местные экономики и «ударить по застоявшимся умам» местных сообществ (по В. О. Ключевскому). Необходимы еще радикальное совершенствование государственной региональной политики, внесение корректив в межбюджетные отношения, в существующее разделение полномочий и предметов ведения между Федерацией и регионами, поправок в законодательную базу недропользования и другие нормативные и правовые акты.

К месту оказался и вопрос об обсуждаемой пенсионной реформе. Суперконтинентальная евразийская территория с одиннадцатью часовыми поясами, громадными различиями в природных и климатических условиях требует дифференцированного подхода к установлению предельного возраста выхода на пенсию. Суровый климат и худшие условия для жизнедеятельности в Сибири и на Дальнем Востоке по сравнению с урало-европейской частью России, слабая освоенность территории, географическая окраинность негативно отражаются на средней продолжительности жизни местных жителей, уступающей среднероссийской на 2,4 года, а также способствуют миграционному оттоку трудоспособного населения с восточных окраин в европейскую зону. Остановить демографическую катастрофу могло бы помочь, в числе других государственных мер, сохранение ныне действующей возрастной шкалы выхода на пенсию гражданам Зауралья. Более того, данный акт, на наш взгляд, мог бы послужить мотивацией для притока трудовых ресурсов в макрорегион, как это уже происходило в советскую эпоху. 
Итак, лишь совместные усилия силами местных, региональных и федеральных органов власти могут создать достаточные условия для экономического прорыва восточных регионов России на внешние рынки.

\section{Литература}

Атанов Н. И., Мункодугарова А. Б. Экономическая динамика Забайкальской России и Монголии: приграничные сравнения трансформационного периода // ЭКО. № 12. 2014. С. 86-98.

Ветитнев А.М., Торгашева А.А. Определение влияния лечебно-оздоровительного туризма на экономику региона // Проблемы современной экономики. 2013. № 4. C. 352-355.

Восток России: проблемы освоения - преодоления пространства / Под ред. В.А. Крюкова и В.В. Кулешова. Новосибирск: Издательство ИЭОПП СО PAH, 2017. 484 c.

Гудков Л., Дубин Б. Сельская жизнь: рациональность пассивной адаптации // Мониторинг общественного мнения: экономические и социальные перемены. 2002. № 6. C. 23-37.

Калугина 3.И. Человеческий потенциал развития приграничных регионов Сибири // ЭКО. 2014. № 11. С. 70-88.

Соболева С. В. Чудаева О. В. Смирнова Н.Е. Григорьев Ю. А. Особенности формирования населения приграничных территорий Сибири// ЭКО. 2014. № 11 . C. $20-35$.

Шагжиев К. Ш., Бабиков В.А. Проблемы развития лечебно-оздоровительного туризма в Республике Бурятия. Региональные аспекты географических исследований и образования. Сборник статей XII Всероссийской научно-практической конференции /Под ред. Н.А. Симаковой, С.Н. Артемовой. 2016. C. $108-111$.

Статья поступила 06.09.2018.

\section{Summary}

Atanov N.I., Buryat State University, Ulan-Ude

Is the Silk Road a Corridor of New Opportunities for the East of Russia or an Indicator of Their Underdevelopment?

The problem of economic integration in the Great silk road project and the Siberian economic corridor is relevant not only for border regions falling into their impact zone, but also for individual municipalities. Analysis of municipal economies in the border areas of the Republic of Buryatia revealed extremely low starting conditions for their integration into the international division of labor. Meanwhile there are significant reserves in the region to increase their economic opportunities. The author proposes some concrete measures at the local, regional and Federal levels to let those municipal economies increase the competitiveness and realize their chance for integration into the trade and economic chains of the external market, including the EAEU and the GSP. 
Great silk road, Eurasian economic Union, economic corridor, municipal areas, local economy, Republic of Buryatia, Baikal region

\section{References}

Atanov N. I., Munkodugarova A. B. (2014) Ehkonomicheskaya dinamika Zabajkal'skoj Rossii i Mongolii: prigranichnye sravneniya transformacionnogo perioda. ECO. [ECO] No.12. Pp. 86-98. (In Russ.)

Vetitnev A. M., Torgasheva A.A. (2013) Opredelenie vliyaniya lechebnoozdorovitel'nogo turizma na ehkonomiku regiona. Problemy sovremennoj ehkonomiki. No. 4. Pp. 352-355. (In Russ.)

Vostok Rossii: problemy osvoeniya - preodoleniya prostranstva (2017). Pod redakciey V.A. Kryukova i V.V. Kuleshova. Novosibirsk. IEHOPP SO RAN Publ., 484 p. (In Russ.)

Gudkov L., Dubin B. (2002) Sel'skaya zhizn': racional'nost' passivnoj adaptacii. Monitoring obshchestvennogo mneniya: ehkonomicheskie i social'nye peremeny. No. 6. Pp. 23-37. (In Russ.)

Kalugina Z.I. (2014) Chelovecheskij potencial razvitiya prigranichnyh regionov Sibiri. ECO .[ECO] No. 11. Pp. 70-88. (In Russ.)

Soboleva S. V. CHudaeva O. V. Smirnova N. E. Grigor'ev YU.A. (2014) Osobennosti formirovaniya naseleniya prigranichnyh territorij Sibiri. ECO.[ECO] No. 11. Pp. 20-35. (In Russ.)

Shagzhiev K.SH., Babikov V.A. (2016) Problemy razvitiya lechebnoozdorovitel'nogo turizma $\mathrm{v}$ Respublike Buryatiya. Regional'nye aspekty geograficheskih issledovanij i obrazovaniya. Sbornik statej XII Vserossijskoj nauchno-prakticheskoj konferencii. Pod redakciey N.A. Simakovoj, S. N. Artemovoj. Pp. 108-111. (In Russ.) 